\title{
Extralinguistics Factors: Motivations in Language Learning Among Malay Students in Negeri Sembilan Malaysia
}

\author{
Rohaidah Kamaruddin, Noor Aina Dani, Nur Amirah Che Soh \\ University Putra Malaysia, Serdang, Malaysia
}

\begin{abstract}
Research on the relationship of second language extralinguistic factors with Malay language achievement among Malay multilingual students at boarding schools in Malaysia is still deficient. Being aware of this fact, the researchers have conducted a study on dominant second language extralinguistic factors in learning a second language. The researchers are interested in studying motivation as one of the main factors in extralinguistic. As a continuation of these efforts, the researchers tried to find the relationship between academic achievement in Malay language by the students and the second language extralinguistic factors. This study uses Dunn \& Dunn Learning Styles, and the Attitude Motivation Test Battery (AMTB) questionnaire created by Gardner. Theory-based questions are constructed in forms of questionnaire and responses are analyzed. The results indicate that there is a relation between language extra-linguistics factors with the bilingual Malay students' achievement in Malay language. This is further ascertained when the research questions are proved right. The results from the field survey and observation study showed that Malay students from Sekolah Berasrama Penuh Integrasi Jempol, Batu Kikir (SBPIJ) choose attitude toward second language speaker identity as the dominant motivation variable, the same as well to Malay students from Sekolah Menengah Sains Tuanku Jaafar, Kuala Pilah (STJ). Emotion produces the main part in motivation.
\end{abstract}

Keywords: extralinguistic, utterance, second language, motivation and emotion

According to The Free Dictionary (2010), the word "extralinguistic" means collective knowledge that is needed to comprehend an utterance and pronunciation. Extralinguistic is the situation beyond the bound of the linguistics, however, it is a free pattern that can exist in any fields of study and the field of language studies, extralinguistic elements are considered because the elements give information about motivation, emotion, behaviour, personality, and so on that are proven helping a student grasp the certain language. In this study, the researchers connected all four ancillaries and extralinguistic in language learning which are essential in order to indicate the perfection of other languages' acceptance besides the mother tongue.

\section{Factors of Extralinguistic}

The literature reviews about extralinguistic in Malaysia was pioneered by Noor Aina Dani (2008) who

Corresponding author: Rohaidah Kamaruddin, Ph.D., Faculty of Modern Language and Communication, University Putra Malaysia, Malaysia; research fields: psycholinguistics and Japanese language. E-mail: rohaidah_k@upm.edu.my.

Noor Aina Dani, Ph.D., Faculty of Modern Language and Communication, University Putra Malaysia, Malaysia; research fields: Psycholinguistics and Malay language. E-mail: aina02@upm.edu.my.

Nur Amirah Che Soh, Master of Arts, Faculty of Modern Language and Communication, University Putra Malaysia, Malaysia; research fields: discourse and analysis. E-mail: miyranur@gmail.com. 
mentioned the factors of extralinguistic exist together with the second language, and it could act as language catalyst and vice versa. The factors of extralinguistic are related to the learning processes whether language learning, science, or mathematics. Noor Aina Dani (1997) based on her study about the extralinguistic elements in language learning toward 109 respondents stated that language exposure and behaviour were two elements of the factors of extralinguistic for the students in the study. Malay language exposure was acquired through the contracts with print media, electronic media, and social interaction. Behaviour was related to the students' personal acceptance toward Malay language and types of motivation.

The survey was carried out in only a district. Since the study was a short term study, the elements of extralinguistic which were studied were also limited to language exposure, behaviour, and motivation. The results of the study were acquired from the research on the questionnaires which had completely been answered by the respondents.

The results of the study by Noor Aina Dani (1997) showed that the language exposure through print media revealed the higher preference of respondents toward reading entertainment magazines and materials. Although the magazines were written in Malay, the language structures were ungrammatical. Sixty-one point forty three percent (61.43\%) of the respondents did not read the newspaper even three days in a week. The respondents who read the newspapers would prefer local newspapers which provide three sections (Malay, English, and Dusun/Kadazan language). Therefore, they would have the options, so their readings did not only focus on Malay section.

The respondents' Malay language exposure through electronic media was limited. The study by Noor Aina Dani (1997) found that more respondents had the engagement with the Malay programs on the radio rather than watching the Malay shows on the television. The duration to listen to the Malay programs is less than two hours and more than half an hour. Besides, there were also local radio channels which used the indigenous languages such as Dusun, Kadazan, Bajau, and Murut.

According to Gooskens's study (2006), the factors of extralinguistic cannot be separated from intelligibility between two languages, for examples, Danish and Swedish. The purpose of the experiment carried out by Schuppert and Gooskens (2011) was not to include two factors of extralinguistic (language exposure and behaviour) in indicating the role of intelligibility with Danish and Swedish. The subjects of the study were native speakers of Danish as many as 19 persons and 26 persons of Swedish native speakers. The subjects of the study were given the task to match 50 cognate nouns with the suitable pictures. The result of the study showed the word recognition score by Danish native speakers stated (63\%) was not obvious compared with the score by Swedish native speakers that stated (65\%). It meant unlike the Swedish native speakers, the Danish native speakers did not show the better performance than Swedish native speakers in the word recognition task. The result showed that the factors of extralinguistic play the important role in the related language intelligibility, and when the factors of extralinguistic expand, the unbalance of language intelligibility will be formed.

In the past researches, most of the factors of extralinguistic were considered as the reason of unbalance in the mutual intelligibility between two languages. In the study, Schuppert and Gooskens (2011) came up with the hypothesis that the unbalance was because of the factors of linguistics, not extralinguistic. The purpose of the research by Schuppert and Gooskens (2011) was to exclude the influences of extralinguistic factors on mutual intelligibility and compare their intelligibility scores with the past researches' scores. To put their research in the perspective, they started the arguments by giving the clear picture of two extralinguistic factors 
which were discussed based on a few opinions of other researchers. The factors of extralinguistic of the second language in the writing context referred to the Malay students' motivation of three groups which are Sekolah Berasrama Penuh Integrasi Jempol (SBPIJ), Sekolah Menengah Sains Tuanku Jaafar, and Sekolah Menengah Sains Rembau in Negeri Sembilan.

\section{Motivation}

Motivation is an essential component in indicating the success of second language learning for the students at school. In this study, the researcher should be focusing on integrative motivation and instrumental motivation. According to Crookes and Schmidt (1991), integrative motivation refers to the student's tendency to indicate their aims in learning the second language. This factor comprises the positive behaviour of the students toward the second language, besides they want to be the society of the second language. Hudson (2000) claimed that instrumental motivation is a desire to gain something practical and concrete through the second language learning, for instance, social reward, economy or improving status in the society. In addition, Gardner (2000) stated that behaviour does not influence directly the second language learning, but behaviour influences the students' motivation. Gardner added that motivation can be well-explained as the combination of someone's effort and desire to achieve the aim of the positive language learning.

Motivation in the second language learning occurs together with behaviour, attitude, and personality. According to Reid (1998), factors of emotion include anxiety (high/low), behaviour (positive/negative), motivation (strong/weak), self-confidence, perseverance, and responsibility. Each student is equipped with their own signs and the intensity of emotion factors. This influences the task of second language learning. Apparently, Reid (1998) took the view that there is the strong relation between the emotion and the types of students' personalities.

Motivation is a concept that is defined in the various ways and dimensions by the researchers in the field of psychology and other scientific fields. As the result, the concept of motivation comprises the inconsistent definitions. In Gardner's study (2005), he referred to the findings of Keller's study (1983) that stated the motivation is the option made up by the individual about experience, aim, and effort to achieve or avoid the certain target.

Commonly, the important feature of motivated individual can be seen through their respective aims. Most individuals have aims, but it cannot be achieved without the characteristics that help them achieve the aims. The motivated individual does not only have the aim, but also they strive hard to achieve the target. They also does not give up easily, and also they have the enthusiasm to achieve the aim that is set. Besides, they also show the strong interest in the activities that need to be gone through before the aim is achieved. The high motivated individual is capable of expecting their own success. When they succeed, they are able to show their high self-confidence, and they are so motivated and determined for each of their own behaviours. Motivation to learn the second language is not instilled easily because it refers to the various aspects of cognitive, affective and behaviour, and also external eagerness. Motivation cannot be indicated by using the scale.

In brief, motivation is a wide concept refers to cognitive, affective, and conative characteristics. All the characteristics can be seen on the motivated individual. Someone may want to learn the certain language because of the purposes that related to integrative orientation or instrumental, however, it needs to be attached with motivation traits. The motivated individual has the reason or motive to get involved in the relevant activity, and they also do not give up easily. They also show the enthusiasm in order to achieve the specific aim. 
Figure 1 shows two types of different variables in language learning which are ability and motivation. The student who has the higher ability (wiseness/smartness and language abilities) is much more successful in learning the language than the student who is less skillful because the student with the high ability will strive hard, give the full attention on their tasks, have their aims, have the strong interest and passion in learning something, and show the high level of confidence about their achievements. According to Gardner (2005), most of education psychologists such as Carroll (1963), Bruner (1966), and Glazer (1976) agreed that ability and motivation are two important factors that related to school achievement.

Figure 1 explains about the ability and motivation as two important factors in context of formal and informal learning. The formal context refers to the teaching process such as in the language class, and the informal context refers to the situation when the language is used and experienced such as listening to the radio, being the committee of the language club, and also using the language for the daily communication. Although ability and motivation involve in the formal context, motivation can be seen clearly in the informal context if it is compared with ability because the motivation tend to indicate whether someone willingly want to get involved in the informal context. It is shown through the dotted arrow that connects the ability to the informal context. Based on the model, both contexts show the way to the result of linguistics and the result of non-linguistics. Eventually, it shows that the situation of education and cultural context have the influence on the motivation not the ability.

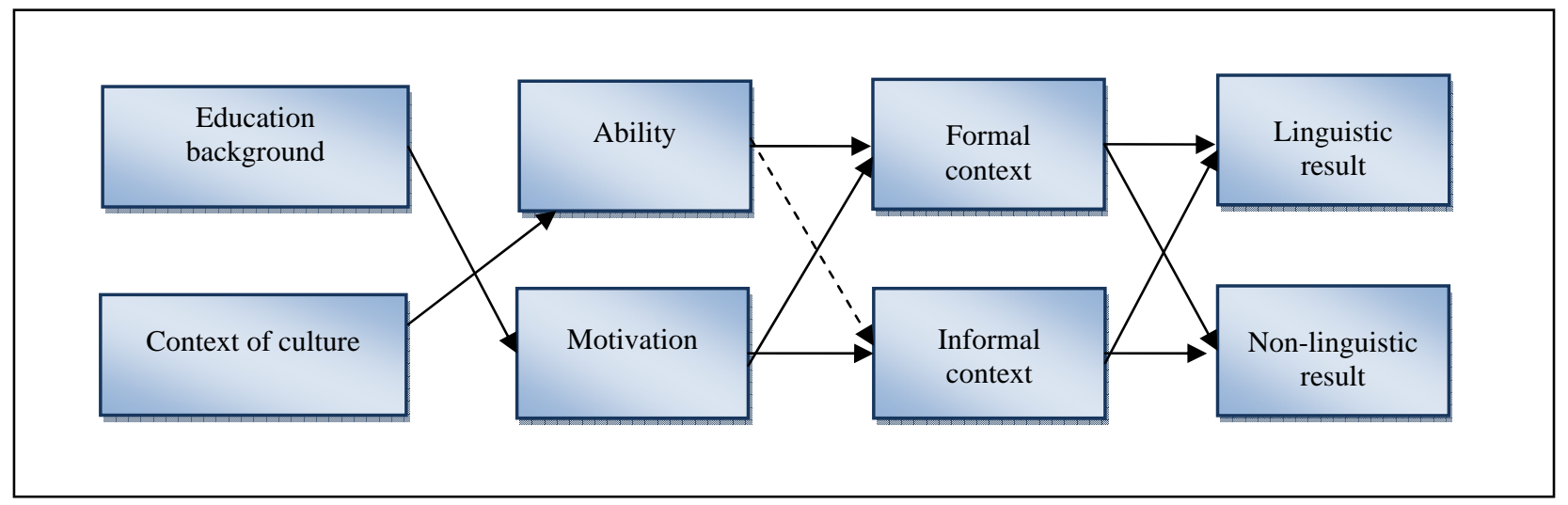

Figure 1. Second language takeover socio-education model. Source: Robert C. Gardner (2005).

It is clear that language acquisition involves the several factors as following:

(1) The quality of teaching - teacher, curriculum, and teaching planning;

(2) The chance to use the language that is learnt;

(3) The context and the sociocultural expectation;

(4) Students’ abilities_-academic (smartness) and language talent;

(5) Affective context - the affected students, behaviour, motivation, and anxiety;

(6) Personality variables;

(7) Learning strategies.

The observation of the seven variables show that the variables are divided into two groups. Factors 1-3 refer to the environment characteristics whereas factors 4-7 are the characteristics of the student. Although the environment characteristics have the important role in learning the language, the characteristics are still in individual control. 
A student could gain the good quality of learning, but the success of the process depends on the student's acceptance.

Model of socio-education (see Figure 2) shows that individual motivation to learn the second language related to these two variables. One of the variables is the behaviour on the situation of the education. Apparently, the natural education situation affects the student's motivation level. The enthusiastic teachers, skillful in the second language, dedicated, the interesting curriculum, the systematic teaching planning, and the good assessment procedure will improve the level of motivation of the student.

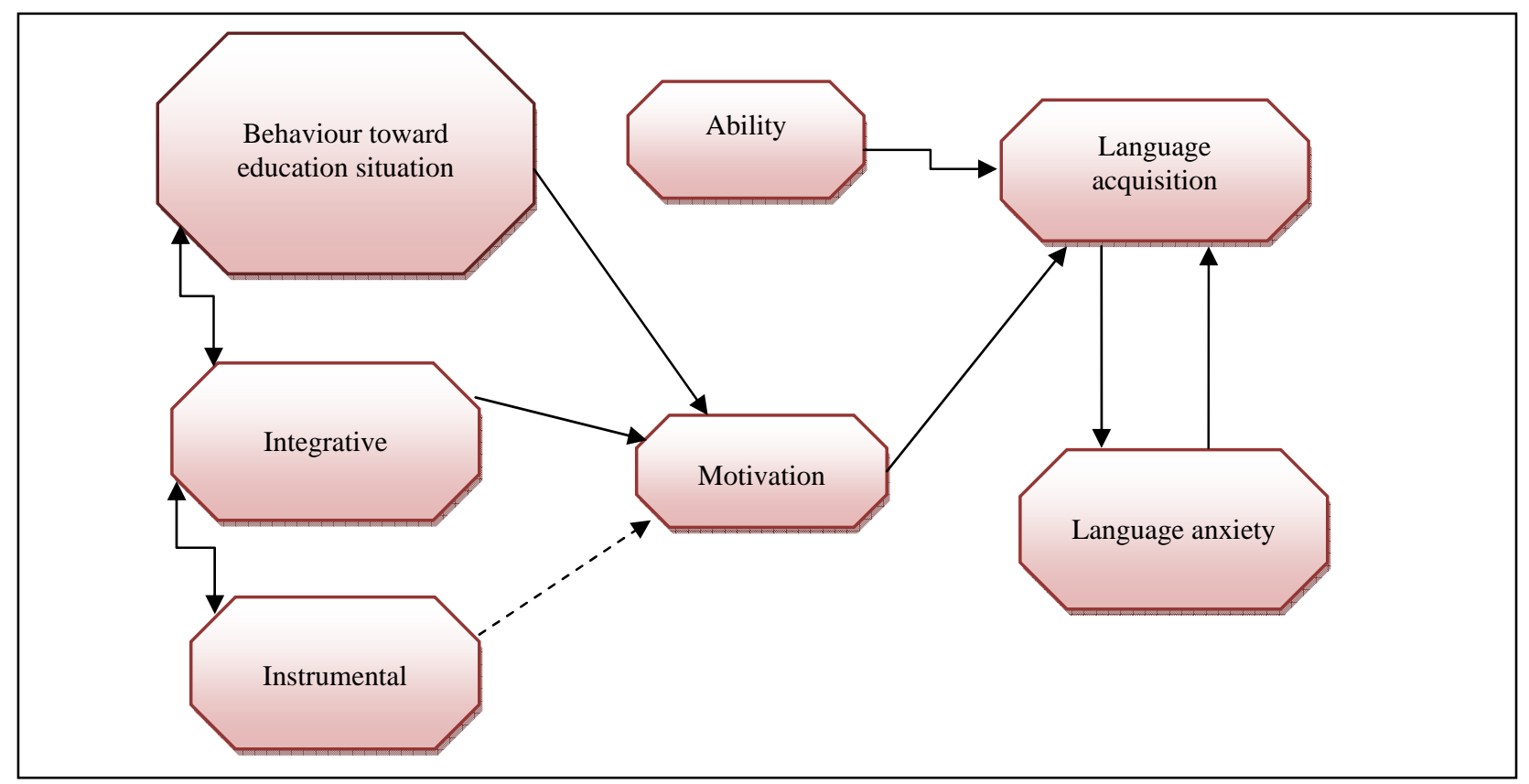

Figure 2. Socio-education model. Source: Robert C. Gardner (2005).

Gardner (2005) referred to the view of Yashima (2002); and Yashima, Zenule-Nishide, and Shimizu (2004), proved that the structure labelled as international posture affects the motivation in the model of structural equality that connects behaviour and motivation to the achievement of the second language or the commitment to speak, and the oftenness to speak the second language. In the study of Yashima et al. (2004), the term of international posture was defined as the behaviour toward the international community that influences the learning process and communication of English language among Japanese students. Behaviour is assessed based on the relation among culture, approach ofteness (purpose of interacting with the foreigners), interest in the global activities, and foreign affairs. International posture also shows the receptivity to others' culture. It is also shown through the research observation that is clearly on the respondents from the SBPIJ and the Sekolah Menengah Sains Tuanku Jaafar (STJ) that those research schools are always visited by the foreign guests from other countries such as Japan, German, and Arab. Receptivity to foreign culture helps the students from the aspect of motivation in learning B2 (second language) and succeeds in every examination for the sake of the career in future.

In addition, instrumental orientation is also involved in the second language achievement. In many kinds of the situations, an individual wants to learn the certain language for the practical reasons. If this concept was related to the achievement, it would be related to the motivation. 
Regarding the discussion about the past researchers' views, so Gardner (2005) created a test called "The Attitude Motivation Test Battery (AMTB)”.

AMTB was created to manage the various of socio-education component in acquiring the second language. There are two types of sub-test, for examples, the test with 10 items and sub-test with four items. The variables of concept that are created to be assessed as follows.

\section{Behaviour Toward the Education Situation}

According to the affective reaction on any of the aspects in the classroom, and it can be evaluated from the aspect of classroom environment, the quality of learning materials, material availability, curriculums, teachers, etc. In the AMTB, these aspects are assessed through participants' opinions about the teachers who get involved in the course.

\section{Integration}

It is assessed using the various ways, and it also represents the affective reaction of the certain group. Integration involves the individual's orientation on the language learning that focuses on the communication between the members of the different language groups. It also comprises the interest in the foreign language group and the behaviour toward the group of the target language. This concept refers the receptiveness to other cultures. The individuals who have the high integration do not only focus on the language community and their nation. In fact, they are well-prepared to accept the features of the language group that are different compared with their own language.

\section{Motivation}

Motivation includes the various aspects. The fundamentals of motivation can be identified through three aspects: evaluating the effort, perseverance, and willing to learn the language. Someone who is motivated has these three features. In the socio-education model, behaviour toward the education situation and integration is the main support of the motivation. It is the same goes to the instrumental, learning motivation, and personality characteristics; however, these features do not even give the huge impact toward the motivation.

\section{Language Anxiety}

Anxiousness about the certain language could rise in various situations, for instances, interpersonal communication, language practices, and tests. It is caused by the type of anxiousness that is more general such as the bad experience in the past or the lack of knowledge and skills in the certain language.

Based on the AMTB of Gardner (2005), the researcher chose 36 items to be ticked by the Malay students from the Sekolah Menengah Sains Rembau (SEMESRA). The elements in those items are important to comprehend the existence of the following variables:

(1) Interest in the second language (B2);

(2) The intensity of the students' motivation;

(3) Behaviour toward learning the second language;

(4) Behaviour toward the second language speakers;

(5) Integrative orientation;

(6) The willing to learn the second language;

(7) Instrumental motivation.

Every item will be answered by ticking any one of the provided likert scale from 1 to 6 . 
The subjects of the research are the excellent students based on their academic achievements, and they were chosen to study at boarding school after getting the excellent result for Malaysia public examination. The research finding result showed that the students' cleverness will give them the high motivation to succeed. It ensures that the students strive to reach their aims in the future.

\section{The Dominant Second Language (B2) Extralinguistic Factors According to a Group of Malay Students as the Studied Subjects}

\section{Motivation Variables}

Elaboration of the dominant second language (B2) extralinguistic factors based on the group of Malay students in the research was started with the motivation. In the theory of monitor (Krashen, 1981), motivation factors are the process beyond the mind that also influence the student's language learning. Motivation is also explained to react and filter out all the unimportant language parts out of the students' mind. To receive the suitable data with the principle of monitor theory, the researcher used the AMTB test by Gardner (2005). The variables of motivation concept that were reported such as the interest in the second language, intensity of the students' motivation, behaviour in learning the second language, behaviour toward the native speakers, integrative orientation, willing in learning the second language, and instrumental motivation. The research data were analysed according to the procedure $\mathrm{min} / \overline{\mathrm{x}}$ by Gardner (2005). The research results about the dominant factors of second language (B2) extralinguistic are based on the research group of Malay students shown in Table 1.

Table 2 shows the motivation of the groups of Malay students from SBPIJ, STJ, and SEMESRA. The dominant motivation for the SBPIJ clearly tends to the behaviour toward native speakers of the second language with mean 35.8. At the same time, the researcher found that the STJ also chose the behaviour toward the native speakers as the most dominant extralinguistic factor. The mean of the STJ is 58.38; on the contrary, the SEMESRA apparently chose the interest in learning the second language (min 149.2).

Table 1

The Dominant Second Language (B2) Extralinguistic Factors According to a Group of Malay Students as the Studied Subjects

\begin{tabular}{llllllll}
\hline & \multicolumn{3}{c}{ Motivation } & \multicolumn{4}{c}{ Extralinguistic factor } \\
\cline { 2 - 8 } & Interest & Intensity & Bhv B2 & Stdnt Bhv & Integrative & Willing & Instrumental \\
\hline SBPIJ & 35.56 & 24.89 & 29.71 & 35.8 & 29.46 & 25.9 & 34.03 \\
STJ & 43.13 & 32.08 & 38.9 & 58.38 & 24.72 & 38.66 & 22.61 \\
SEMESRA & 149.2 & 77.28 & 120.26 & 126.54 & 120.75 & 108.67 & 118.33 \\
\hline
\end{tabular}

Notes. Interest: interest in the second language; intensity: intensity of the students' motivation; Bhv B2: behaviour in learning the second language (B2); Stdnt Bhv: behaviour toward the native speakers; integrative: integrative orientation; willing: willing in learning the second language; instrumental: instrumental motivation.

Next, the order of extralinguistic factors of the motivation variables according to the priority of the groups of Malay students is shown in Table 2. The data of the dominant second language extralinguistic factors according to the each group priority show the SBPIJ chose the behaviour toward the native speakers of the second language as the most dominant (mean 35.8), followed by the interest (mean 35.56), instrumental (min 34.03), behaviour (B2) (mean 29.71), integrative (mean 29.46), willing (mean 25.9), and the last one is the intensity (mean 24.89). According to Krashen (1981), three types of motivation are found to influence the students' second language learning, they are integrative motivation, instrumental motivation, and social group 
qualification motivation. Integrative motivation is a willing to join the society that speaks the second language which is being learnt by the student. Instrumental motivation is a willing to use the learnt language for the practical purposes, for example, to get a job. Motivation of the social group qualification is a willing to gain the skills of the spoken language of the social group which are qualified by the students.

Table 2

Order of Extralinguistic Factors of Motivation Based on the Priority of the Study of Malay Students' Group

\begin{tabular}{|l|l|}
\hline Schools & Order of extralinguistic factor of motivation \\
\hline SBPIJ & 1. Student behavior; 2. Interest; 3. Instrumental; 4. Behaviour (B2); 5. Integrative; 6. Willing; 7. Intensity \\
\hline STJ & 1. Student behaviour; 2. Interest; 3. Behaviour (B2); 4. Willing; 5. Intensity; 6. Integrative; 7. Instrumental \\
\hline SEMESRA & 1. Interest; 2. Student behaviour; 3. Integrative; 4. Behaviour (B2); 5. Instrumental; 6. Willing; 7. Intensity \\
\hline
\end{tabular}

Note. Source: field work (2011).

The background history of the establishment of the selected boarding schools in this study shows that the SBPIJ started operating in 2002. The exposure of the native speaker language (B2) started being implemented among the students in 2005. The SBPIJ would always welcome the visits of the students from Japan for the program of mobility and exchange students. Over the years, all the exposures which had been gained by the students from the exchange native speakers of the second language gave the positive and beneficial impacts to the SBPIJ students. The more presences of the second language native speakers had motivated all the local students to learn the second language. At the same time, they need to get the excellent result for Malay language in order to maintain the ranking as the best boarding school.

Motivation also triggers the strong interest while the Malay students learn the second languages as the elective and compulsory subjects. It is good as the situation where the students of boarding schools have the exposures and opportunities to get involved in any kinds of contests that related to the second languages which are carried out at the local level or international level, for examples, Japanese Speech Contest, Germany Story Telling, Lantern Fiesta and Moon Cake, and various contests of English language such as International Symposium on Nature, English Debate and English in Camp.

The situation of the students from the SBPIJ is similar to the students of the STJ. The data of the dominant second language extralinguistic factors based on the priority of the STJ respondents showed that the behaviour toward the native speakers of the second language as the most dominant (mean 58.38), followed by interest (mean 43.13), behaviour toward the second language (B2) (mean 38.9), interest (mean 38.66), intensity (mean 32.08), integrative (mean 24.72), and the last one is the instrumental (mean 22.61).

The selection of the similar extralinguistic concept variables could be identified by the researcher for the both boarding schools. The reasons were respondents that felt impressed about the native speakers of the second language; it does not matter whether the native speaker is a teacher or student. According to Azizi Yahaya (2006), extrinsic motivation occurs from the external stimulation to encourage someone in doing the certain activity that is beneficial for one's self. The types of stimulations for the extrinsic motivation are like the compliments, incentives, gifts, grades, and environment climate that is conducive to encourage the students in learning. The second language learning is different because the stimulations have the additions such as the native speakers, artists, songs, cartoons, dramas, and cinemas.

As the answer for the first objective, the results of the study showed the extrinsic motivation of the SBPIJ and STJ students was high. The behaviour of admiring the second language native speakers motivated the 
students of the SBPIJ and STJ to be interested in the second language besides strived to succeed in the subject of Malay language.

The selection of the extralinguistic concept variables for the SEMESRA was different. The results of the survey about the dominant second language extralinguistic factors based on the priority of each group for motivation factor showed that the SEMESRA respondents chose the interest toward the foreign languages as the second language for the most dominant (mean 149.2), followed by behaviour toward the second 1 anguage native speakers (mean 126.54), integrative (mean 120.75), behaviour toward the second language (mean 120.26), instrumental (mean 118.33), willing (mean 25.9), and intensity (mean 24.89) as the last option.

The students who have the intrinsic motivation do not need the incentives or rewards because all the activities that were carried out already gave them the reward and satisfaction. Azizi Yahaya (2006) stated that someone might get the high intrinsic motivation if a psychology situation motivated them to do something that they are interested in. As the answer for the first objective of the study, the results of the study showed that intrinsic motivation of the SEMESRA students was at the high level. It showed that the SEMESRA students have the internal motivation that exists of the interest factor to learn and succeed in the second language (B2) learning. The survey result of the SEMESRA was different compared with the other two boarding schools which are the SBPIJ and STJ.

The finding of the study by the researcher is similar to the finding of Ainol Madziah Zubairi and Isarji $\mathrm{Hj}$ Sarudin (2009) which the finding showed two interesting findings existed from the study. First, the Malaysian students were so motivated to learn the foreign language because of the extrinsic and intrinsic reasons, for example, student reported that they had learnt the foreign language because of extrinsic reasons such as the career in the future, to make them have more knowledge or to fulfill the requisite to graduate.

The researcher thinks that the differences are clear because the students were not exposed with the presence of the second language native speakers. It was because of the situation that the school just started operating in 2009, and the students mostly the intake of the excellent Malaysia Lower Secondary Examination students with straight " $\mathrm{A}$ " for eight subjects. The students were the second intake for the form 4 students of the SEMESRA. The interest especially in pursuing the study abroad after Sijil Pelajaran Malaysia examination caused the students to put the high target to succeed. Gardner (2005) and Krashen (1981) called this kind of interest as the instrumental motivation.

\section{The Conclusion of the Relation Between Malay Students' Achievements of Malay Language and the Second Language (B2) Extralinguistic Factors}

The relation between the second language (B2) extralinguistic factors and Malay language achievement of the Malay students at the SBPIJ, STJ, and SEMESRA is acquired through the analysis of correlation Spearman Rho. The result of the analysis as follows.

\section{Extralinguistic Factor of Motivation}

The results of the study showed the relation between Malay language achievements of Malay students and the interest in the second language stated the significant correlation at the alpha level of 0.074; meanwhile, there is a strong relation between Malay students' achievements in Malay language and the motivation intensity in the second language that showed the significant correlation at the alpha level of 1.000 .

The firm relation could be seen between the Malay students' achievements in Malay language and the 
willing to learn the second language, the achievements of Malay students in Malay language and instrumental motivation in the second language showed the significant correlation at the alpha level of 0.074 .

Besides the results of the interest, willing, motivation intensity, and instrumental motivation through the SPSS 18 test, it apparently showed the relation between Malay language achievements of Malay students and instrumental motivation in the second language set the significant correlation at the alpha level of 0.074 . The similar result of the relation between Malay language achievements of Malay students and the behaviour toward the second language native speakers showed the significant correlation at the alpha level of 0.074 . The similar correlation 0.074 was acquired through the relation between Malay language achievements of Malay students and behaviour in learning the second language. The relation between the dependent variables (students' marks of Malay language) and the second language extralinguistic factors (motivation, behaviour, emotion, and personality) as the independent variables produced the Spearman Rho correlation between the positive coefficient 0.074 and the perfect level of positive coefficient 1.000. The data represented three schools that were studied by the researcher. In a conclusion, there are a strong positive relation and a strong perfect positive relation between Malay students' achievements in Malay language and the second language extralinguistic factor from the aspect of motivation.

\section{References}

Bruner, J. S. (1966). Toward a theory of instruction. New York: Horton.

Carroll, J. B. (1963). A model of school learning. Teachers College Record, 64, 723-733.

Crookes, G., \& Schmidt, R. W. (1991). Motivation: Reopening the research agenda. Language Learning, 41(4), 469-512.

Dani, N. A. (1997). Teori Monitor dan hipotesisnya (Monitor theory and the hypothesis). Jurnal Dewan Bahasa, 41(5), $494-504$.

Dani, N. A. (2008). Penguasaan dan Penyelidikan Bahasa (Mastering language research). Kuala Lumpur: Gateway Publishing House Sdn. Bhd

Gardner, I. (2000). Problems and inconsistencies with Kolb’s learning styles. An International Journal of Experimental Educational Psycology, 20(3), 341-348.

Gardner, R. C. (2005). Integrative motivation and second language acquisition. Proceedings from the Canadian Association of Applied Linguistics/Canadian Linguistics Association Joint Plenary Talk. May 30, London, Ontario.

Glazer, R. (1976). Components of a psychology of instruction: Toward a science of design. Review of Educational Research, 46, 1-24.

Gooskens, C. (2006). Linguistic and extra-linguistic predictors of inter-Scandinavian communication. In J. van de Weijer and B. Los (Eds.), Linguistics in the Netherlands 23 (pp. 101-113). Amsterdam: John Benjamins.

Goudas, M., Dermitzaki, I., \& Bagiatis, K. (2001). Motivation in physical education is correlated with participation in sport after school. Psychological Reports, 88(2), 491-496.

Hudson, G. (2000). Essential introductory linguistics. Hong Kong: Blackwell Publishers.

Keller, J. M. (1983). Motivational design of instruction. In C. M. Reigeluth (Ed.), Instructional design theories and models (pp. 386-433). Hillsdale, NJ: Erlbaum.

Krashen. (1981). Second language acquistion and second language learning. Oxford: Pergamon Press.

Reid, M. J. (1998). Learning styles in the ESL/EFL classroom. New Jersey, USA: Prentice Hall.

Schuppert, A., \& Gooskens, C. (2011). The role of extra-linguistic factors in receptive bilingualism: Evidence from Danish and Swedish pre-schoolers. International Journal of Bilingualism, 16(3), 332-347.

Yahaya, A. (2006). Menguasai Penyelidikan: Teori, Analisis \& Interpretasi Data (Master of research in education: Theory, analysis and interpretation of data). Selangor: PTS Publications \& Distributors Sdn. Bhd.

Yashima, T. (2002). Willingness to communicate in a second language: The Japanese EFL context. The Modern Language Journal, 86, 54-56.

Yashima, T., Zenuke-Nishide, L., \& Shimizu, K. (2004). The influence of attitudes and affect on willingness to communicate and second language communication. Language Learning, 54, 119-152.

Zubairi, A. M., \& Sarudin, I. H. (2009). Motivation to learn a foreign language in Malaysia. GEMA Online Journal of Language Studies, 9(2), 73-86. 